\title{
Clostridium difficile toxin A excites enteric neurones and suppresses sympathetic neurotransmission in the guinea pig
}

\author{
Y Xia, H Z Hu, S Liu, C Pothoulakis, J D Wood
}

\begin{abstract}
Background and aims-Evidence suggests that the intestinal actions of Clostridium difficile toxin A-stimulation of secretion and motility, and an acute inflammatory response-have a neurally mediated component.

Methods-Direct intracellular electrophysiological recording of electrical and synaptic behaviour in enteric neurones was performed in the submucous plexus of guinea pig small intestine during exposure to the toxin.

Results-Application of toxin A affected both the electrical behaviour of the neuronal cell bodies and inhibitory noradrenergic neurotransmission to the cell bodies. Altered electrical behaviour included depolarisation and increased excitability. Tetrodotoxin or a histamine $\mathrm{H}_{2}$ receptor antagonist did not affect the depolarisation evoked by toxin A. Failure of the histamine antagonist to suppress the actions of toxin $A$ is evidence that its actions were not mediated by degranulation of intramural mast cells. The action of toxin $A$ on neurotransmission was suppression of inhibitory postsynaptic potentials evoked in the neuronal cell bodies by stimulation of sympathetic nerve fibres that synapsed with the cell bodies. The inhibitory postsynaptic potentials were mediated by norepinephrine (noradrenaline) acting at postsynaptic alpha adrenoceptors on the cell bodies. Hyperpolarising responses evoked in the cell bodies by micropressure application of norepinephrine were unaf-
\end{abstract}

Accepted for publication 3 November 1999
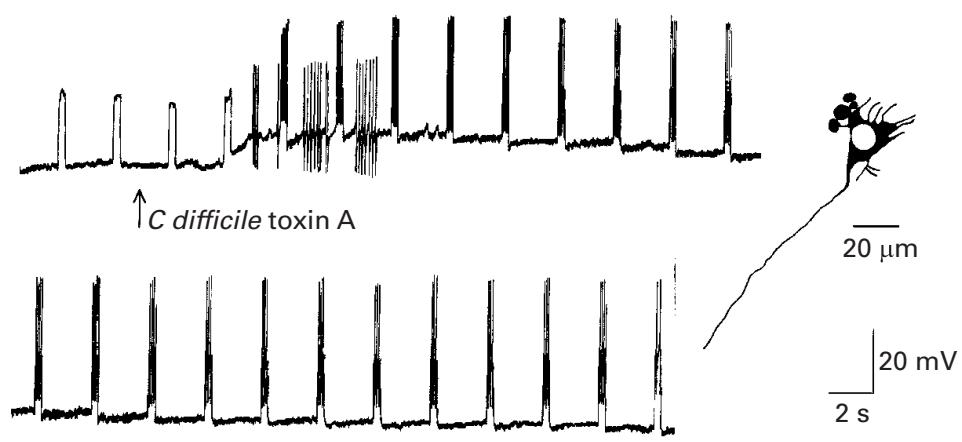

Figure 1 Application of $C$ difficile toxin $A$ by pressure microejection depolarised and enhanced the excitability of neurones in the submucous plexus. The top and bottom records are continuous. The neurone failed to discharge action potentials in response to intraneuronal injection of rectangular depolarising current pulses before application of the toxin. After application, slowly activating depolarisation of the membrane potential occurred. The depolarisation was accompanied by enhanced excitability as reflected by repetitive action potential discharge evoked by intraneuronal current injection and spontaneous spike discharge. The neurone had uniaxonal morphology. fected by toxin A. This fulfils criteria for a presynaptic inhibitory action of toxin $A$ to suppress release of norepinephrine from sympathetic postganglionic axons.

Conclusions-Results suggest that the neural component of the action of toxin $A$ involves both direct excitation of enteric neurones and suppression of norepinephrine release from postganglionic sympathetic nerve fibres in the enteric nervous system.

(Gut 2000;46:481-486)

Keywords: enteric nervous system; enterotoxins; diarrhoea; intestine

Clostridium difficile is a non-invasive toxigenic bacterium identified as the primary cause of antibiotic associated diarrhoea and colitis in humans. ${ }^{12}$ Toxigenic strains of $C$ difficile release two large molecular weight proteinaceous exotoxins identified as toxins $\mathrm{A}$ and $\mathrm{B}$. Toxin $\mathrm{A}$ (TX-A) is responsible for diarrhoea and an acute mucosal inflammatory response in animal models. ${ }^{3}$

Introduction of purified TX-A into the lumen of intestinal loops stimulates influx of neutrophils and activates an enteric neural programme for enhanced secretion and powerful propulsive motility. Blockade of enteric nerves with tetrodotoxin suppresses these effects and suggests that an initial site of action for the enterotoxin is on neural elements of the enteric nervous system. Treatment with a non-peptide tachykinin NK-1 antagonist or with mast cell stabilising drugs also prevents the transmigration of polymorphonuclear leucocytes into the gut from the circulation. ${ }^{4-6}$ Responses to the enterotoxin include upregulation of substance $\mathrm{P}$ in lumbar dorsal root ganglia and small bowel mucosa in association with elevations in substance P mRNA. ${ }^{7}$ Responses to the toxin do not occur in mast cell deficient mice. ${ }^{8}$ This suggests that enteric nervous input utilising substance $\mathrm{P}$, which is a putative transmitter for slow synaptic excitation in enteric neuronal circuits, ${ }^{9}{ }^{10}$ reinforces mast cell degranulation and the release of chemoattractant factors for inflammatory cells as well as biogenic amines, eicosinoids, and cytokines.

The aim of the present study was to investigate the suggestion that $C$ difficile TX-A acts directly on intramural enteric neural elements.

Abbreviations used in this paper: EPSP, excitatory postsynaptic potential; IPSP, inhibitory postsynaptic potential; TX-A, $C$ difficile toxin A; TTX, tetrodotoxin. 


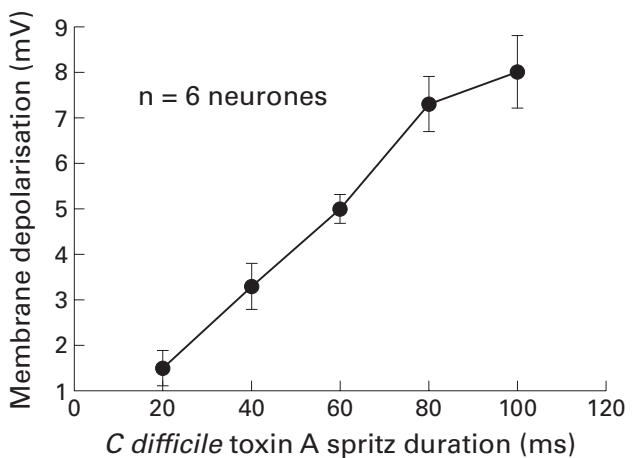

Figure 2 The amplitude of the depolarising response to $C$ difficile toxin $A$ increased with increasing amounts of toxin when the toxin was applied by pressure microejection. The amount of toxin applied was increased by progressively increasing the duration of the microejection pulses.

We used intracellular microelectrode recording methods and intraneuronal marking techniques to study the actions of TX-A on electrical and synaptic behaviour of morphologically identified neurones in the submucous plexus of guinea pig small intestine. A preliminary report of the results has appeared in abstract form. ${ }^{11}$

\section{Methods}

Male Hartley strain guinea pigs (400-600 g) were sacrificed by stunning and exsanguination according to procedures approved by the Ohio State University Laboratory Animal Care and Use Committee. Segments of small intestine

A

$$
\text { Control }
$$

B

Cimetidine $(100 \mu \mathrm{M})$
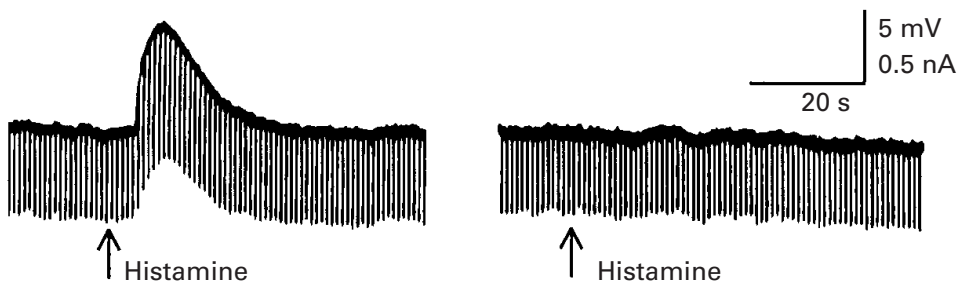

C

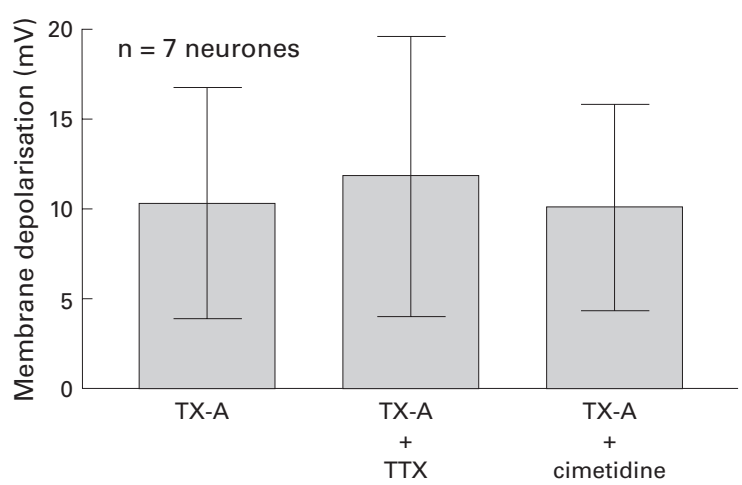

Figure 3 The depolarising responses evoked by histamine and toxin $A(T X-A)$. ( $A$ ) Microejection pulse of $100 \mu \mathrm{M}$ histamine depolarised the neurone. Depolarisation was associated with increased input resistance as reflected by increased amplitude of electrotonic potentials produced by intraneuronal injection of constant current hyperpolarising pulses. (B) Pretreatment with $100 \mu \mathrm{M}$ cimetidine blocked the response to histamine. (C) Neither $100 \mu M$ cimetidine nor $2 \mu M$ tetrodotoxin (TTX) significantly suppressed the depolarising action of $C$ difficile $T X-A$. This suggested that the action of $T X-A$ was directly on the neurones from which the recordings were obtained rather than because of release of histamine from mast cells or transmitter release from presynaptic terminals. were removed $20 \mathrm{~cm}$ orad to the ileocaecal junction. Preparations of the submucous plexus for electrophysiological recording were microdissected as described previously. ${ }^{12}$ The preparations were mounted in a $2.0 \mathrm{ml}$ recording chamber that was perfused at a rate of $10-15 \mathrm{ml} / \mathrm{min}$ with Krebs solution warmed to $37^{\circ} \mathrm{C}$ and gassed with $95 \% \mathrm{O}_{2}-5 \% \mathrm{CO}_{2}$ to buffer at $\mathrm{pH}$ 7.3-7.4. The composition of the Krebs solution was (in $\mathrm{mM}$ ) NaCl, $120.9 ; \mathrm{KCl}$, 5.9; $\mathrm{MgCl}, 1.2 ; \mathrm{NaH}_{2} \mathrm{PO}_{4}, 1.2 ; \mathrm{NaHCO}_{3}, 14.4$; $\mathrm{CaCl}, 2.5$; and glucose, 11.5.

Methods of intracellular recording from the submucous plexus are described in detail elsewhere. ${ }^{10}$ Transmembrane electrical potentials were recorded with conventional "sharp" microelectrodes. The microelectrodes were filled with $4 \%$ biocytin in $2 \mathrm{M} \mathrm{KCl}$ containing $0.05 \mathrm{M}$ Tris buffer ( $\mathrm{pH} 7.4$ ). Resistances of the electrodes were 80-190 M $\Omega$. The intraneuronal marker (biocytin) was injected by the passage of hyperpolarising current. The preamplifier (M767, World Precision Instruments, Sarasota, Florida, USA) had bridge circuitry for injection of electrical current. All data were recorded on videotape for later analysis. Synaptic potentials were evoked by electrical shocks $(0.1-20 \mathrm{~Hz})$ applied focally to interganglionic connectives with $20 \mu \mathrm{m}$ diameter Teflon insulated platinum wire electrodes.

Actions of pharmacological agents and TX-A were studied by pressure microejection or by application in the superfusion solution. Micropipettes (10 $\mu \mathrm{m}$ tip diameter), manipulated with the tip close to the impaled neurone, were used to microeject the substances. Pressure pulses of nitrogen with predetermined force and duration were applied to the micropipettes through electronically controlled solenoid valves. Duration of the pressure pulses could be increased in increments of $1 \mathrm{~ms}$ from 0 to 1 seconds. Stepwise increases in pulse duration were used to assess, in a quasi manner, the dependence of TX-A effects on concentration.

Toxin A was purified to homogeneity from broth culture supernatants of $C$ difficile strain 10463 as described previously. ${ }^{13}$ Norepinephrine (noradrenaline), phentolamine, tetrodotoxin (TTX), and cimetidine were all obtained from Sigma Biochemicals, St Louis, Missouri, USA. Data are expressed as mean (SEM). Student's $t$ test for unpaired values was used to evaluate significance of differences for means of resting membrane potential and neuronal input resistance.

\section{Results}

EXCITATORY ACTIONS OF TX-A

Application of TX-A was by pressure microejection. Limitations on the supply of TX-A because of constraints of isolation in sufficient quantities restricted ability to obtain concentration-response data by adding the toxin to the superfusion reservoir of the recording chamber. The microejection pipettes contained $0.6 \mathrm{mg} / \mathrm{ml} \mathrm{TX-A}$ in Krebs solution and were positioned with the tips $20-50 \mu \mathrm{m}$ from the impaled neurone. Dilution of the ejected toxin occurred rapidly in the $2 \mathrm{ml}$ volume of the tissue chamber which was perfused 
A
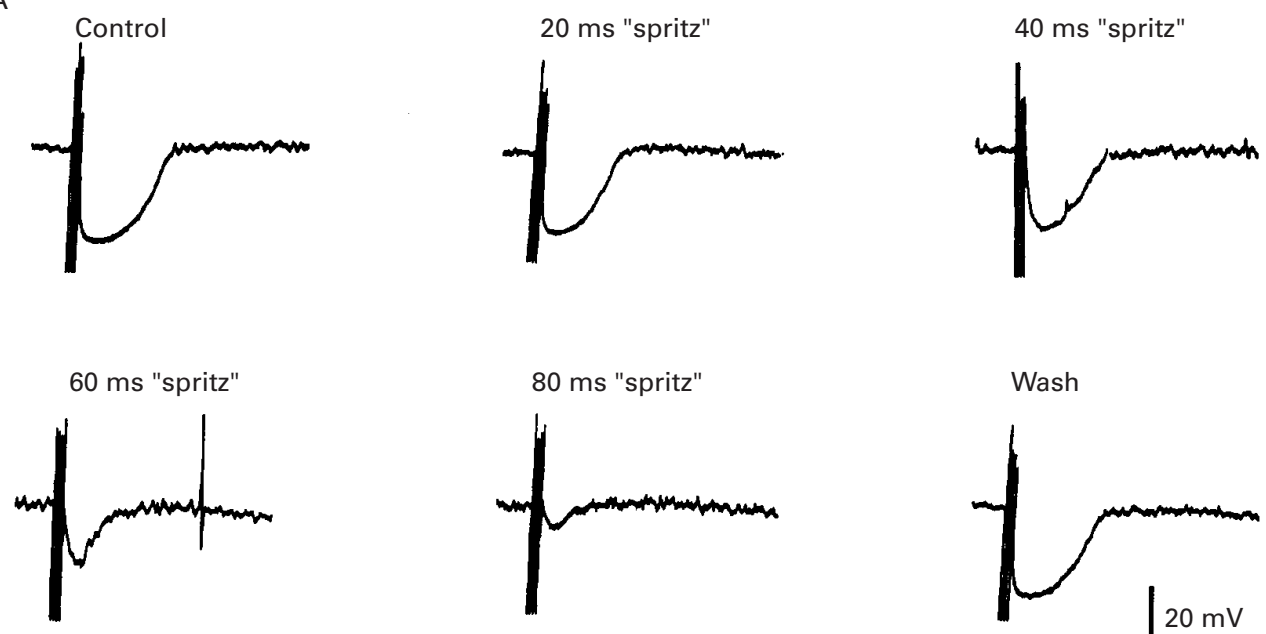

$80 \mathrm{~ms}$ "spritz"

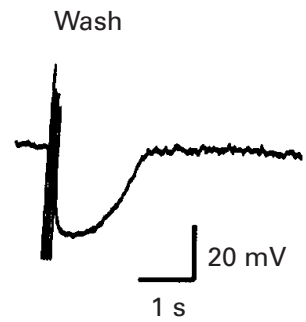

B
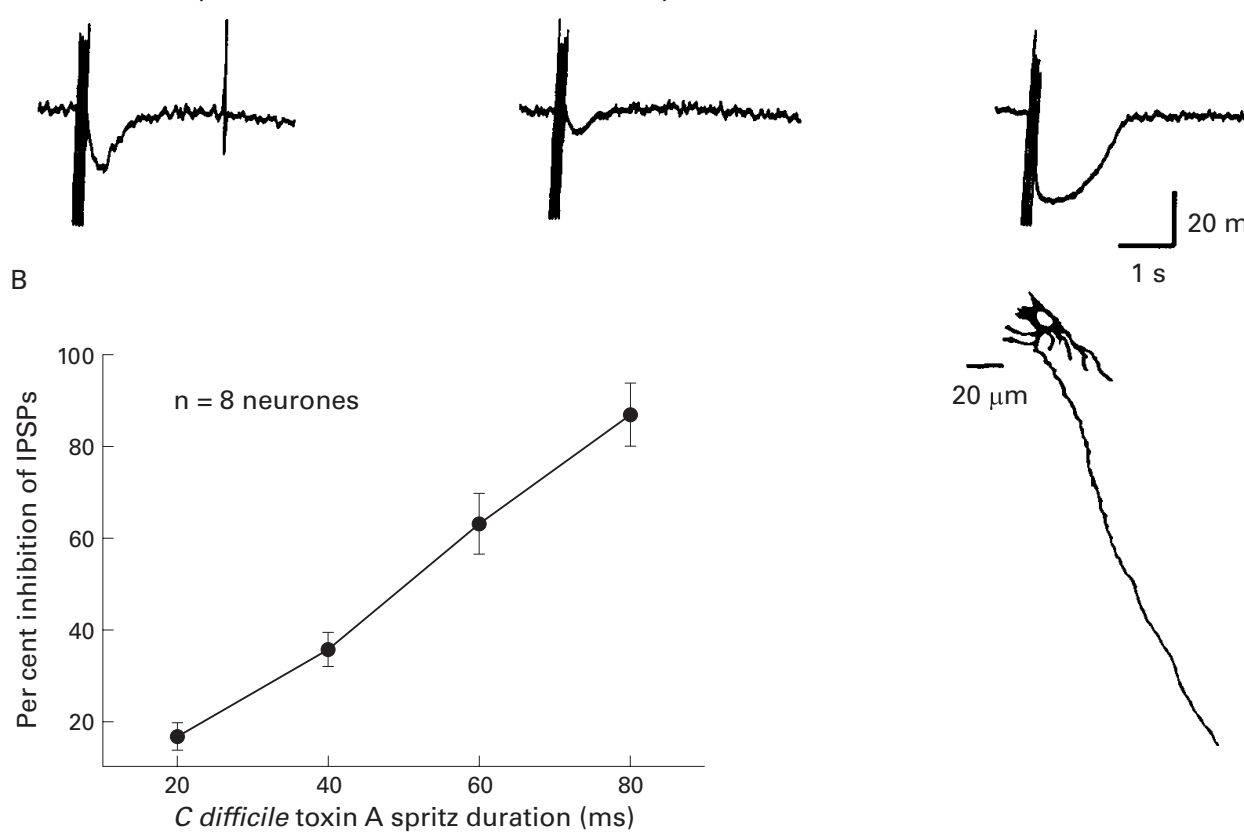

Figure 4 Focal electrical stimulation of sympathetic noradrenergic synaptic inputs to submucous plexus neurones evoked inhibitory postsynaptic potentials (IPSP). (A) Application of $C$ difficile toxin $A(T X-A)$ suppressed the stimulus evoked IPSP. Suppression of the IPSP was concentration dependent as reflected by a progressive decrease in the amplitude of hyperpolarisation with progressively increased duration of micropressure pulses ("spritz") from 20 to $80 \mathrm{~ms}$ in a single neurone. (B) Quantitative concentration-response data for eight neurones. The neurone in A had uniaxonal morphology.

at a rate of $10-15 \mathrm{ml} / \mathrm{min}$. Precise determination of effective concentrations (for example, $\mathrm{EC}_{50}$ ) was not possible with this method.

TX-A, applied by micropressure ejection, evoked excitatory responses in 23 of 24 neurones (nine AH type and $14 \mathrm{~S}$ type cells). Micropressure pulses of Krebs solution alone evoked no responses. The effects of TX-A consisted of membrane depolarisation coincident with increased input resistance. Augmented excitability was apparent as spontaneous spike discharge or repetitive discharge during intracellular injection of depolarising current pulses (fig 1). These effects were accompanied by suppression of the characteristic hyperpolarising after potentials in $\mathrm{AH}$ type neurones. The amplitude of the depolarising responses increased with increased duration of pressure ejection pulses ranging from 20 to $110 \mathrm{~ms}$ (fig $2)$. This was indicative of concentration dependence of the responses. The effects were reversed as TX-A was washed from the recording chamber.

The excitatory responses to TX-A were reminiscent of excitation of submucous neurones produced by degranulation of antigen sensitised mucosal mast cells. ${ }^{14}{ }^{15}$ One of the mediators released by mast cell degranulation is histamine, which acts at the histamine $\mathrm{H}_{2}$ receptor subtype to depolarise and enhance excitability of neurones in the guinea pig submucous plexus. ${ }^{14-16}$

We used the $\mathrm{H}_{2}$ histamine receptor antagonist, cimetidine, to determine whether the excitatory responses to TX-A might be a secondary effect of degranulation of mast cells and the release of histamine. Cimetidine is known to block the excitatory actions of exogenously applied histamine and of histamine released by mast cells during antigen exposure in sensitised guinea pig bowel in vitro. ${ }^{14-16}$

Pretreatment with cimetidine blocked the neuronal excitatory responses to micropressure pulses of histamine, but did not change significantly the depolarising responses to TX-A (fig 3). This suggested that the excitatory action of TX-A was directly on the neurones and not secondary to mast cell activation by the toxin.

Excitatory responses evoked by TX-A (membrane depolarisation) were also unaffected by pretreatment with TTX (fig 3). This suggested direct action of the toxin because TTX was expected to block axonal conduction in the plexus and thereby prevent input to the recorded neurone from synaptically connected neurones elsewhere in the microcircuit. 
TX-A SUPPRESSION OF INHIBITORY POSTSYNAPTIC POTENTIALS

Focal electrical stimulation of sympathetic noradrenergic synaptic inputs to the submucous neurones evoked inhibitory postsynaptic potentials (IPSPs) (fig 4A). Micropressure application of norepinephrine mimicked the hyperpolarising component of the IPSPs (fig 5A). Blockade of the IPSPs (fig 5D-F) by the alpha adrenoceptor antagonist, phentolamine, was consistent with earlier reports that the noradrenergic IPSPs in guinea pig submucosal
A

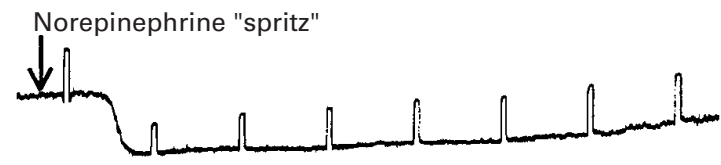

Phentolamine (1 $\mu \mathrm{m})$

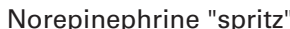
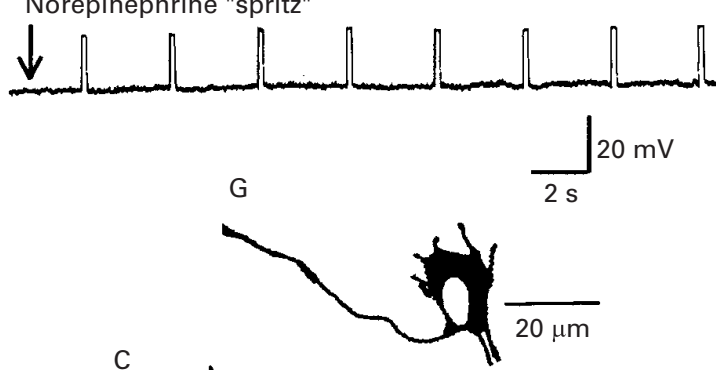

C

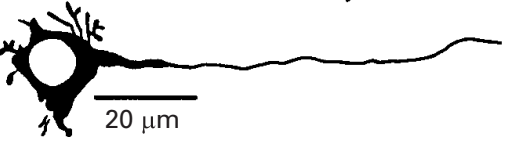

D Control IPSP

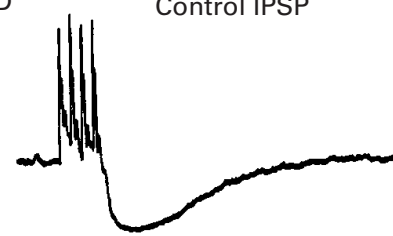

$E$

Phentolamine $(1 \mu \mathrm{m})$

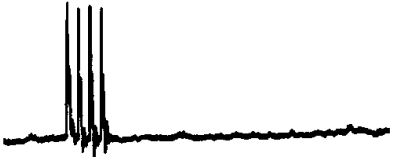

$\mathrm{F}$

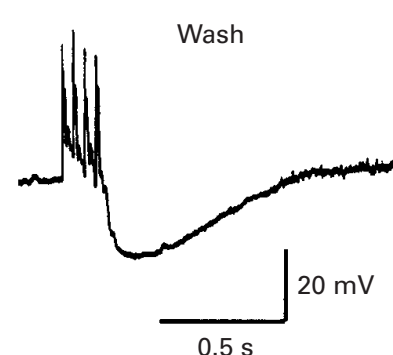

Figure 5 The alpha adrenergic blocking drug, phentolamine, blocked both the hyperpolarising responses to micropressure application of norepinephrine (noradrenaline) and stimulus evoked inhibitory postsynaptic potentials (IPSP). (A) Micropressure ("spritz") application of $10 \mu \mathrm{M}$ norepinephrine evoked a hyperpolarising response accompanied by decreased input resistance. Decreased input resistance was reflected by decreased amplitude of electrotonic potentials produced by intrasomal injection of constant current depolarising pulses. (B) Blockade of norepinephrine evoked response by phentolamine. (C) The neurone in $A$ and B had uniaxonal morphology. (D) Focal electrical stimulation of an interganglionic connective evoked and IPSP. (E) Blockade of the IPSP by phentolamine. (F) Reversal of phentolamine induced blockade following washout of the drug. $(G)$ The neurone in $D$ and $F$ had uniaxonal morphology.

A

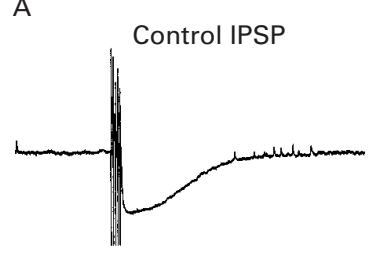

D

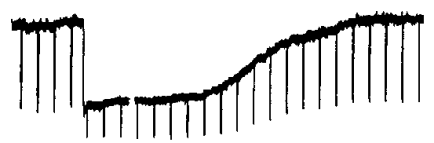

$\uparrow$

Norepinephrine "spritz"
B

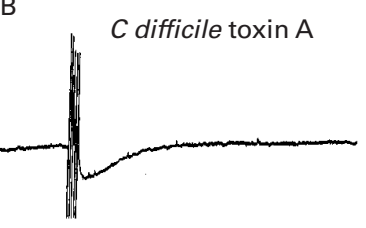

C difficile toxin A
C

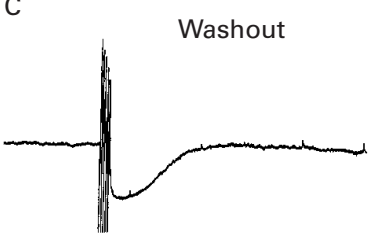

$\mathrm{F}$

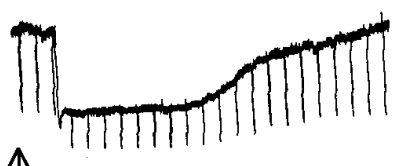

Figure 6 Toxin A (TX-A) suppressed stimulus evoked noradrenergic inhibitory postsynaptic potentials (IPSP) but not the hyperpolarising responses to exogenously applied norepinephrine (noradrenaline). (A) Control IPSP. (B) Suppression of IPSP by micropressure pulse of TX-A. (C) Recovery of IPSP after washout of TX-A. (D) Hyperpolarising response to micropressure pulse of norepinephrine. (E) Hyperpolarising response to norepinephrine during exposure to TX-A was unchanged. (F) Hyperpolarising response to norepinephrine after washout of $T X-A$. All records are from the same neurone. Downward deflections in $D-F$ are electrotonic potentials produced by intraneuronal injection of constant current hyperpolarising pulses. 
plexus neurones are mediated by alpha noradrenergic receptors. ${ }^{12}{ }^{17}$ Application of TX-A from microejection pipettes reversibly suppressed or abolished the stimulus evoked IPSPs (fig 4A). Suppression of the IPSPs was concentration dependent as determined by progressively increasing the duration of micropressure pulses of TX-A (fig 4A,B). Blockade of the IPSPs was accompanied by an increase in spontaneously occurring fast excitatory postsynaptic potentials that sometimes reached threshold for action potential discharge (fig $4 \mathrm{~A})$. The excitatory postsynaptic potentials probably reflected input from synaptically connected neurones that were excited by the toxin.

Micropressure application of norepinephrine evoked phentolamine sensitive hyperpolarising responses associated with decreased input resistance in the submucous neurones (fig 5A,B; fig 6D-F). Application of TX-A had no effect on the hyperpolarisation evoked by norepinephrine while it suppressed the stimulus evoked IPSP in the same neurones (fig $6 \mathrm{~A}-\mathrm{C})$. In eight neurones, the mean hyperpolarisation to $20 \mathrm{~ms}$ duration micropressure pulses of norepinephrine was $30(2.4) \mathrm{mV}$ in the absence of TX-A and 29.3 (2.3) $\mathrm{mV}$ when preceded by pulses of TX-A that suppressed the IPSP. This suggested that the site of action of TX-A was at presynaptic inhibitory sites on the noradrenergic nerve terminals, and that suppression of the IPSPs resulted from inhibition of norepinephrine release from the terminals.

\section{Discussion}

The results suggest that purified $C$ difficile TX-A has direct actions on neurones in the submucous plexus of guinea pig small intestine in relatively low concentrations. Nevertheless, absolute concentration data could not be determined precisely in the present study because of limitations on the amounts of available toxin. Two kinds of actions were revealed. One was an excitatory action at the level of the membranes of the neuronal cell bodies that was reminiscent of the excitatory action of cholera toxin on submucosal neurones. ${ }^{18}$ The excitatory action of TX-A mimicked slow synaptic excitatory responses characteristically found in enteric neurones. ${ }^{10}$ Excitation evoked by TX-A also mimicked the slow excitatory effects produced by paracrine release of histamine from mucosal mast cells. ${ }^{14-16}{ }^{19}$ Failure of histamine receptor antagonists and blockade of axonal conduction by TTX to suppress the excitatory responses to TX-A are evidence for direct action at the somal membranes of the neurones. The excitatory action could not be attributed to activation of other neurones that provided synaptic input to the recorded neurone or to secondary effects of mast cell degranulation.

The second action of TX-A was suppression of IPSPs evoked by stimulation of release of norepinephrine from sympathetic postganglionic nerve fibres. This appeared to be a direct presynaptic action that suppressed release of norepinephrine from the noradrenergic terminals because the toxin did not suppress the

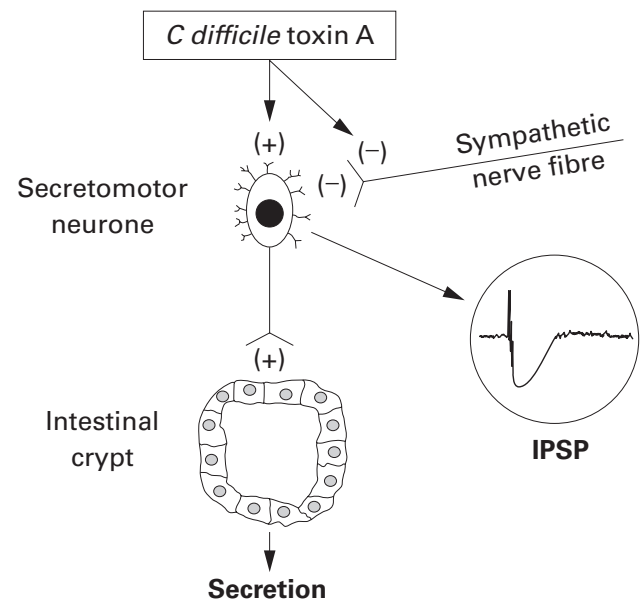

Figure 7 Heuristic model for action of $C$ difficile toxin $A$ $(T X-A)$ in the enteric nervous system. TX-A acts directly to increase excitability of neurones and to suppress release of norepinephrine (noradrenaline) at sympathetic synapses on submucous neurones. Stimulation of submucosal secretomotor neurones is expected to evoke secretion from mucosal crypts and may account in part for diarrhoeal symptoms associated with $C$ difficile enteritis. Inactivation of sympathetic braking action on secretomotor neurones facilitates secretion and may also contribute to diarrhoeal symptoms.

hyperpolarising action of exogenously applied norepinephrine. The presynaptic inhibitory action of TX-A differed from that of cholera toxin which was reported not to suppress IPSPs in submucous neurones. ${ }^{18}$

An aspect of the pathophysiological significance of the neuronal action of TX-A is illustrated in fig 7. Secretomotor neurones to the intestinal crypts are located in the submucous plexus. When secretomotor neurones fire, they release vasoactive intestinal polypeptide and/or acetylcholine at the neuroepithelial junctions and this stimulates the secretion of water and electrolytes into the crypt lumen. ${ }^{20}$ Hyperactivity of the secretomotor neurones is associated with a state of secretory diarrhoea. Two neuronal actions of TX-A are expected to be involved in production of the secretory state. One is direct excitation by the toxin of the secretomotor neurones and/or interneurones that provide excitatory synaptic drive to the secretomotor neurones. The other is the inhibitory action of TX-A on noradrenergic transmission to the secretomotor neurones and/or synaptically connected interneurones. This effectively nullifies any sympathetic braking action on the secretomotor neurones to permit maximal secretomotor firing rates and hyperstimulation of mucosal secretion.

Aside from submucous secretomotor neurones, a major component of sympathetic input to the intestine acts at presynaptic terminals to prevent release of excitatory transmitter substances that mediate fast or slow transmission at synapses within the integrated circuits of the enteric nervous system. ${ }^{21}$ These axo-axonal synapses, which have been described ultrastructurally, function to inactivate the excitatory synaptic circuitry that mediates intestinal motility. ${ }^{22}$ Application of norepinephrine or electrical stimulation of sympathetic postganglionic fibres in the intestinal mesentery reduces or abolishes fast nicotinic transmission 
in the enteric networks. ${ }^{23}{ }^{24}$ This occurs without any change in the somal membrane properties during exposure to norepinephrine and without any change in the depolarising responses of the neurones to microejected acetylcholine. Both findings are evidence that the mechanism of action of norepinephrine is blockade of release of acetylcholine from presynaptic nerve terminals. The presynaptic inhibitory receptors have been identified as the $\alpha_{2}$ adrenoceptor subtype. ${ }^{25}$ Based on the neurophysiology of the synaptic interface between the sympathetic and enteric divisions of the autonomic nervous system, the significance of TX-A induced blockade of norepinephrine release at excitatory synapses is expected to be prevention of sympathetic inactivation of the enteric microcircuits that generate intestinal motor activity and other intestinal behaviours during $C$ difficile enteritis.

This work was supported by National Institutes of Health grants RO1 DK-37238 and RO1 DK-46941 to JDW.

1 Pothoulakis C, Castagliuolo I, LaMont JT. Nerves and intestinal mast cells modulate responses to enterotoxins. News Physiol Sci 1998;13:58-63.

2 Kelly CP, Pothoulakis C, LaMont JT. Clostridium difficile colitis. N Engl f Med 1994;330:257-62.

3 Kelly C, Becker S, Linevsky JK, et al. Neutrophil recruitment in Clostridium difficile toxin A enteritis in the rabbit. F Clin Invest 1994;93:1257-65.

4 Pothoulakis C, Castagliuolo I, La Mont JT, et al. CP96,345, a substance $\mathrm{P}$ antagonist, inhibits rat intestinal responses to Clostridium difficile toxin-A but not cholera toxin. Proc Natl Acad Sci USA 1994;91:947-51.

5 Pothoulakis C, Karmeli F, Kelly CP, et al. Ketotifen inhibits Potostridium difficile toxin A-induced enteritis in rat ileum. Gastroenterology 1993;105:701-7.

6 Castragliuolo I, LaMont JT, Letourneau R, et al. Neuronal involvement in the intestinal effects of Clostridium difficile toxin A and Vibrio cholerae enterotoxin in rat ileum. Gas toxin A and Vibrio cholerae ente
troenterology 1994;107:657-65.

7 Castagliuolo I, Keates AC, Qiu BS, et al. Increased substance $\mathrm{P}$ responses in dorsal root ganglia and intestinal macrophages during Clostridium difficile toxin A enteriti in rats. Proc Natl Acad Sci USA 1997;94:4788-93.

8 Wershil BK, Castagliuolo I, Pothoulakis C. Direct evidence of mast cell involvement in Clostridium difficile toxin A-induced enteritis in mice. Gastroenterology 1998;114 956-64.
9 Katayama Y, North RA, Williams JT. The action of substance $\mathrm{P}$ on neurones of the myenteric plexus of the guinea-pig small intestine. Proc R Soc Lond 1979;206:191208.

10 Wood JD. Physiology of the enteric nervous system. In: Johnson LR, ed. Physiology of the gastrointestinal tract. 3rd ed. New York: Raven Press, 1994:423-82.

11 Xia Y, Pothoulakis C, Wood JD. Clostridium difficile toxin excites enteric neurones and suppresses inhibitory noradrenergic neurotransmission in the submucous plexus of guinea-pig small intestine [abstract]. Gastroenterology 1997; 112:A1122.

12 Zafirov DH, Cooke HJ, Wood JD. Elevation of cAMP facilitates noradrenergic transmission in submucous neurones of guinea-pig ileum. Am f Physiol 1993;264:G442-6.

13 Pothoulakis C, LaMont JT, Eglow R, et al. Characterization of rabbit ileal receptors for Clostridium difficile toxin A. Evidence for a receptor-coupled G protein. F Clin Invest 1991;88:119-25.

14 Frieling T, Cooke HJ, Wood JD. Neuroimmune communication in the submucous plexus of guinea-pig colon after sensitization to milk antigen. Am f Physiol 1994;267: G1087-93.

15 Frieling T, Palmer JM, Cooke HJ, et al. Neuroimmune communication in the submucous plexus of guinea pig colon after infection with Trichinella spiralis. Gastroenterology 1994;107:1602-9.

16 Frieling T, Cooke HJ, Wood JD. Histamine receptors on submucous neurones in the guinea-pig colon. Am f Physiol 1992;264: G74-80.

17 North RA, Surprenant A. Inhibitory synaptic potentials resulting from alpha ${ }_{2}$ adrenoceptor activation in guinea-pig submucous plexus neurones. $\mathcal{F}$ Physiol Lond 1985;358:1733

18 Jiang MM, Kirchgessner A, Gershon MD, et al. Cholera toxin-sensitive neurones in guinea pig submucosal plexus. Am f Physiol 1993;264:G86-94.

19 Wood JD. Histamine signals in enteric neuroimmune interactions. Ann NY Acad Sci 1992;664:275-83.

20 Cooke HJ, Reddix RA. Neural regulation of intestinal electrolyte transport. In: Johnson LR, ed. Physiology of the gastrointestinal tract. 3rd ed. New York: Raven Press, 1994: 2083-132.

21 Wood JD. The synaptic interface between the sympathetic and enteric divisions of the autonomic nervous system. In: Chey W, ed. Functional bowel disorders. New York: Raven Press, 1982:87-91.

22 Manber L, Gershon MD. A reciprocal adrenergiccholinergic axoaxonic synapse in the mammalian gut. Am $\mathcal{F}$ Physiol 1979;5:E738-45.

23 Nishi S, North RA. Intracellular recording from the myenteric plexus of the guinea-pig ileum. F Physiol Lond myenteric plexus
1973;231:471-91.

24 Hirst GDS, McKirdy HC. Presynaptic inhibition at a mammalian peripheral synapse. Nature Lond 1974;250:430-1.

25 Surprenant A, North RA. Mechanism of synaptic inhibition by noradrenaline acting at alpha ${ }_{2}$ adrenoceptors. Proc $R$ Soc Lond 1988;234:85-114. 